\title{
Growth of Pyrocarbon by Multi-Physics Fields Chemical Vapor Infiltration
}

\author{
Mingyu Zhang*, Zhiyong Xie, Zhean Su, Qizhong Huang and Jianxun Chen
}

State Key Laboratory for Powder Metallurgy, Central South University, Changsha 410083, China

\begin{abstract}
A novel rapid chemical vapor infiltration (CVI) processing defined by multi-physics fields CVI was used to fabricate carbon/carbon $(\mathrm{C} / \mathrm{C})$ composites. Liquid petrol gas is used as carbon source and the parameters were experimental tested and optimized. The influence of temperature and pressure on the growth of pyrocarbon was investigated in detail. Because of the influence of multi-physics fields, a new surface morpha is grown under control parameters. It is called "Dot Structure". The structure of pyrocarbon is analyzed and characterized by XRD, SEM with EDS, and Raman spectrum. At the end, a simple model of point discharge for growth of pyrocarbon is proposed. The deposited pyrocarbon based on multi-physics fields chemical vapor infiltration is expected to provide an improve performance in rapid $\mathrm{C} / \mathrm{C}$ composites fabrication.
\end{abstract}

Keywords: Chemical vapor infiltration, carbon/carbon composites, pyrocarbon, microstructure, characteristics.

\section{INTRODUCTION}

Carbon/carbon $(\mathrm{C} / \mathrm{C})$ composites are attractive materials for use at high temperature in inert atmosphere and ablative environments which makes them suitable for aviation and aerospace applications. But the high manufacture cost restrains $\mathrm{C} / \mathrm{C}$ composites widely application. At present, the full cycle ICVI manufacture of $\mathrm{C} / \mathrm{C}$ composites needs thousands of hours. On the other hand, with the rapid densification technology, the cost can be greatly lowered [1]. Therefore, the developed countries focus study on rapid CVI technology, such as CLVI, forced flow CVI $[2,3]$ and so on.

On the basis of previous researches and our experiments, our group developed the multi-physics fields CVI (MFCVI) which is a new rapid densification technology [4], which provide a new way to fast densify $\mathrm{C} / \mathrm{C}$ composites. Based on this technology, pyrocarbon with a new surface morpha is grown with control process parameters.

\section{EXPERIMENTAL}

A cold wall reactor was used to chemical vapor infiltrate liquefied petroleum gas (LPG) into 2.5D carbon felt which original density is $0.1 \mathrm{~g} \cdot \mathrm{cm}^{-3}$ with nitrogen as diluent gas. Schematic diagram of infiltration is presented in Fig. (1). A piece of graphite paper with a thickness $0.2 \mathrm{~mm}$ was put into the middle of two pieces of felt with a size of the rectangular-shaped felt $300 \mathrm{~mm}(\mathrm{~L}) \times 40 \mathrm{~mm}(\mathrm{~W}) \times 20 \mathrm{~mm}$ $(\mathrm{H})$ and when current passing the sandwich structure and the gas brushing the felt surface, thermal gradient, chemical gradient and even an electromagnetic gradient are built. Firstly, the influence of temperature and pressure was investigated by a set of experiments. Secondly, two materials were processed with this technique. The first, smooth laminar (SL) was infiltrated at $750{ }^{\circ} \mathrm{C}, 12 \mathrm{kPa}$ at a fixed residence time. The second, a pyrocarbon with new morpha was infiltrated at $650{ }^{\circ} \mathrm{C}, 12 \mathrm{kPa}$ at the same residence time.

*Address correspondence to this author at the State Key Laboratory for Powder Metallurgy, Central South University, Changsha 410083, China; Tel: +86-731-88877671; E-mail: mingyu@mail.csu.edu.cn
The third, rough laminar (RL) was fabricated by isothermalisobaric chemical vapor infiltration (ICVI) from a mixture of methane and hydrogen. The specimen of columns perpendicular to the graphite paper was cut out for analysis. All samples have been infiltrated for $20 \mathrm{~h}$ and high temperature treated at $2300{ }^{\circ} \mathrm{C}, 2 \mathrm{hrs}$.

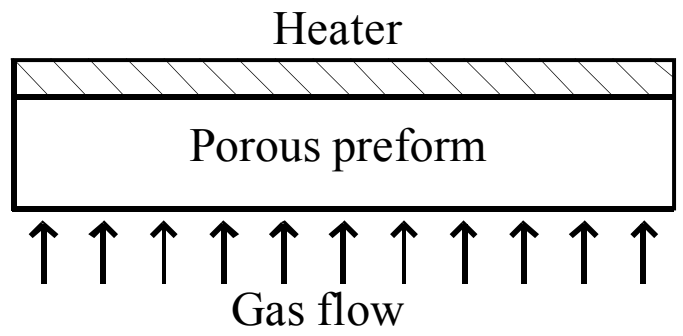

Fig. (1). Schematic diagram of CVI process.

The textures of pyrocarbon at different deposition ring were investigated by Raman spectra. Raman spectra were recorded on a JOBIN YVON-Lab Ram HR800. Raman spectroscope using $\mathrm{He}-\mathrm{Ne}$ laser $(632.8 \mathrm{~nm})$, with the laser beam focused to $1 \mu \mathrm{m}$ in diameter on polished surface of the composites, used to analyze microstructure at different deposition ring of pyrocarbon.

\section{RESULTS AND DISCUSSION}

$\mathrm{C} / \mathrm{C}$ composites were fabricated with multi-factor physics fields CVI by forming gradient of temperature and electromagnetism. As is shown in Fig. (1), The heating layer located in the center of the felt enables a coupling of gradient of temperature and electric current density. It leads to the gradient of absorbability for depositing species before forming carbon. It was found that multi-factor physics fields CVI can improve the infiltration rate effectively. The deposition temperature ranged from $550{ }^{\circ} \mathrm{C}$ to $650{ }^{\circ} \mathrm{C}$, and total pressure $4 \mathrm{kPa}$. And then the influence of pressure on the growth of pyrocarbon at temperature of $650{ }^{\circ} \mathrm{C}$ has also been investigated, the pressure varying from 0.1 to $15 \mathrm{kPa}$. 

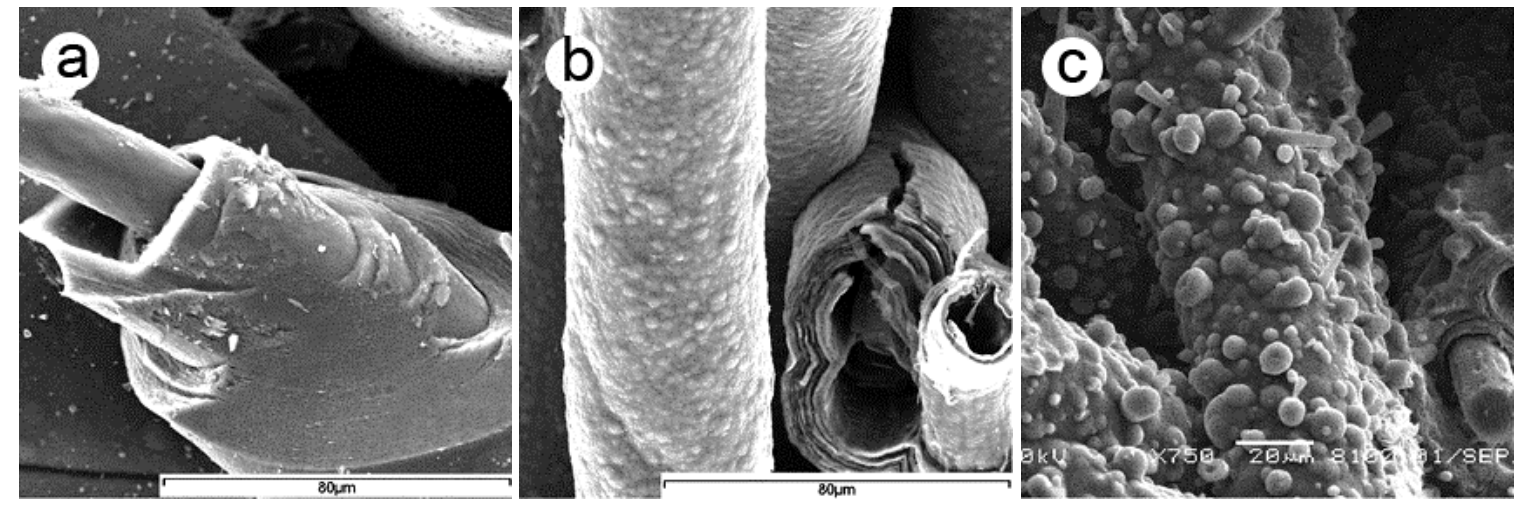

Fig. (2). SEM images of the temperature influence on the growth of pyrocarbon at $4 \mathrm{kPa}, 550{ }^{\circ} \mathrm{C}(\mathbf{a}), 600{ }^{\circ} \mathrm{C}(\mathbf{b}), 650{ }^{\circ} \mathrm{C}(\mathbf{c})$, respectively.

The surface of pyrocarbon changes with the temperature, as shown in Fig. (2). At $550^{\circ} \mathrm{C}$, its deposition surface is very smooth and compact; the fracture surface shows conchoidal structure. With the temperature increasing to $600{ }^{\circ} \mathrm{C}$, a few nuclei appear on the pyrocarbon surface (Fig. 2b), the fracture surface shows samdwich. At $650{ }^{\circ} \mathrm{C}$, a lot of grown nuclei were observed on the pyrocarbon surface. The mushroom-like and cone-like carbon can also be observed. The broken points indicate that the nuclei are hollow.

As Fig. (3) shown, lower pressure produces few nuclei and deposition surface is smooth, as shown in Fig. (3a). With increasing pressure, a few nuclei can be observed. The nuclei increases rapidly with pressure increasing to $15 \mathrm{kPa}$, similar to the temperature influence.
Fig. (4) shows three typical polarized-light optical photographs of polished cross-sections and Raman analysis location in the $\mathrm{C} / \mathrm{C}$ composites, corresponding to Fig. (2). Fig. (4a) exhibits well defined extinction crosses, few discernible growth feature, grey layers, corresponding to smooth laminar(SL) structure; Fig. (4b), in contrast, displays numerous, irregular extinction crosses, many growth features, showing close feature of rough laminar (RL) structure; Fig. (4c) exhibits few extinction cross and has low optical reflectivity, lots of growth cones outwards.

Fig. (5) shows the spectra of pyrocarbon in the $\mathrm{C} / \mathrm{C}$ composites at different deposition ring. The shape of the $\mathrm{D}$ and $G$ peaks [5] of the DS pyrocarbon reveals fewer graphite crystallites and dominant crystallites by three fold over four fold coordination. The middle $\mathrm{FWHM}_{\mathrm{D}}$ indicates a little
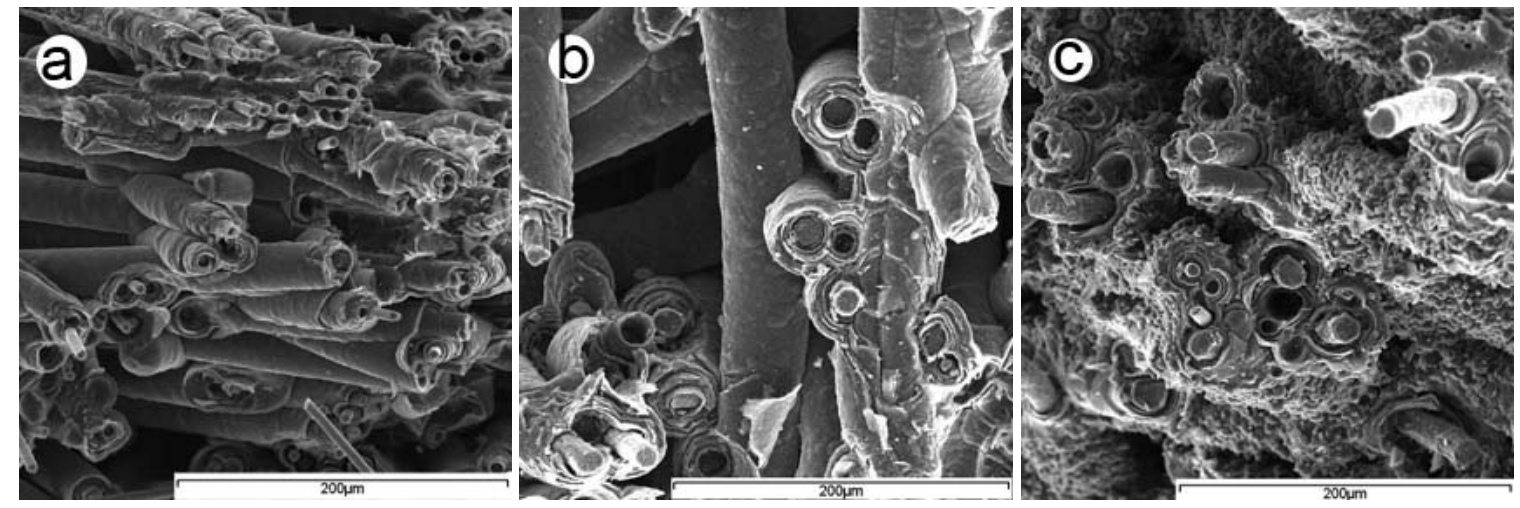

Fig. (3). SEM images of the pressure influence on the growth of pyrocarbon at $650{ }^{\circ} \mathrm{C}, 0.1 \mathrm{kPa}(\mathbf{a}), 4 \mathrm{kPa}(\mathbf{b}), 15 \mathrm{kPa}(\mathbf{c})$, respectively.
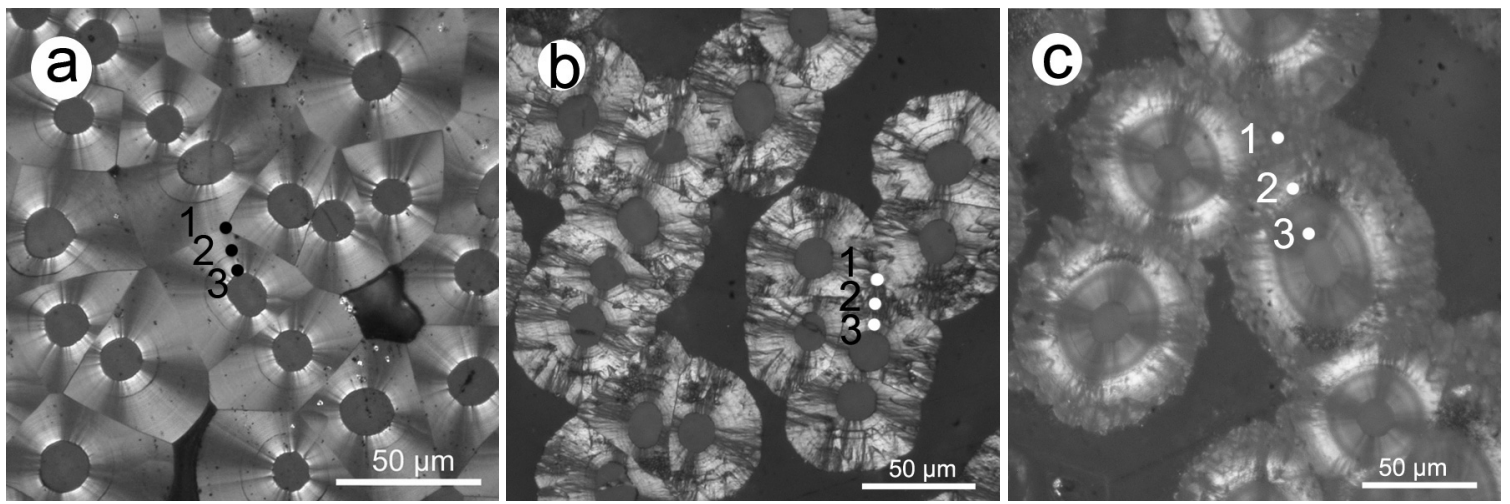

Fig. (4). Polarized optical micrographs of pyrocarbon at $4 \mathrm{kPa}$ and $550{ }^{\circ} \mathrm{C}(\mathbf{a}), 600{ }^{\circ} \mathrm{C}(\mathbf{b}), 650{ }^{\circ} \mathrm{C}(\mathbf{c})$, respectively and the numbers indicate Raman analysis location. 
more nano-crystallite character than RL pyrocarbon. The $\mathrm{FWHM}_{\mathrm{G}}$ of DS pyrocarbon reveals a higher orientation of the graphene layers. The ratio of the $\mathrm{D}$ to $\mathrm{G}$ peak intensity, $\mathrm{I}_{\mathrm{G}} / \mathrm{I}_{\mathrm{D}}$, is proportional to the degree of graphitization of pyrocarbon in micro-area, and used to evaluate the process parameters on microstructure [6]. The sample (a) show lower values and less drastic change in different deposition ring. High values in Fig. (5b) indicate that the deposition microarea lies at a suitable process parameters. Fig. (5c) shows the drastic change of ratio value of $\mathrm{I}_{\mathrm{G}} / \mathrm{I}_{\mathrm{D}}$. There is abnormally highest value outer ring, much lower in middle and interior ring. The transition is abrupt and the change of deposition micro-area may induce the transition. It is called "Dot Structure" on its polarized light microscopy in this work.

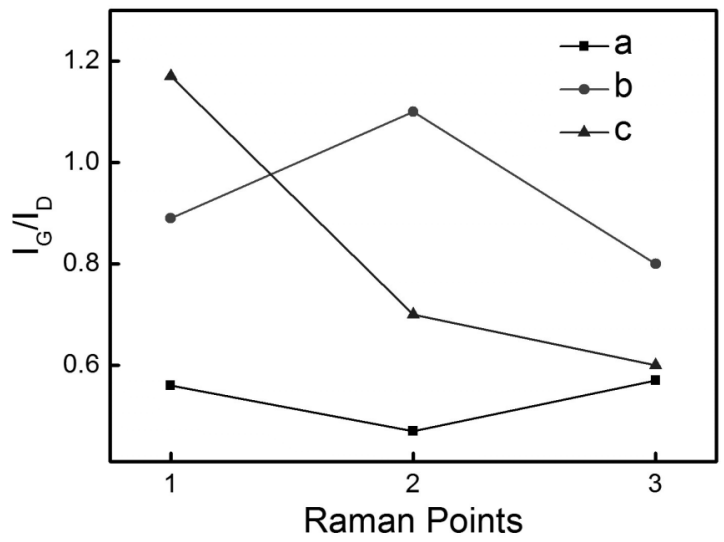

Fig. (5). Raman spectra of pyrocarbon of different deposition ring shown in Fig. (4) at $4 \mathrm{kPa}$ and $550{ }^{\circ} \mathrm{C}(\mathbf{a}), 600^{\circ} \mathrm{C}(\mathbf{b}), 650{ }^{\circ} \mathrm{C}(\mathbf{c})$, respectively.
Optical observation under polarized light is the first characterization performed on the matrix. The texture of pyrocarbon was ranged within Lieberman and Pierson's classification. The material obtained by ICVI is RL pyrocarbon as shown in Fig. (6b). The extinction angle is the maximum: $\mathrm{Ae}=21^{\circ}$ with the striated features in the branches of the Maltese-cross. The composite with smooth laminar (SL) matrix is shown in Fig. (6c) which exhibits a typical smooth extinction by rotating the stage under cross-polar. The extinction angle is $\mathrm{Ae}=12^{\circ}$. It means a low anisotropy. A mixed structure of pyrocarbon (called DS by us) can be observed in Fig. (6a). It shows no obvious Maltese-cross and extinction angle with deep blue and orange colors. Meanwhile, it is noticeable that a lot of huge cones present in the matrix.

Morphologies of different textures by SEM are given in Figs. $(\mathbf{7}, \mathbf{8})$. Fig. (7) is the deposition surface of pyrocarbon. Fig. (8) shows the fracture surfaces of pyrocarbon by high resolution scanning electron microscopy. The SL pyrocarbon deposited on the carbon fibers has a smooth surface in Fig. (7c) while the cross-section is rough and waved in Fig. (8c). The RL pyrocarbon has a rough surface with numerous balllike protuberances in Fig. (7b) but the fracture surface is smooth and flat laminar in Fig. (8b). The surface of DS pyrocarbon deposited has a lot of nodular textures and hollow cones growing up and down while the fracture surface is the sawtooth-like layers with a certain angle.

Energy disperse spectrum (EDS) of pyrocarbon is shown in Fig. (9). There is no indication to show any catalytic elements contained in the materials. The XRD pattern (Not shown at here) also shows that only one single element,

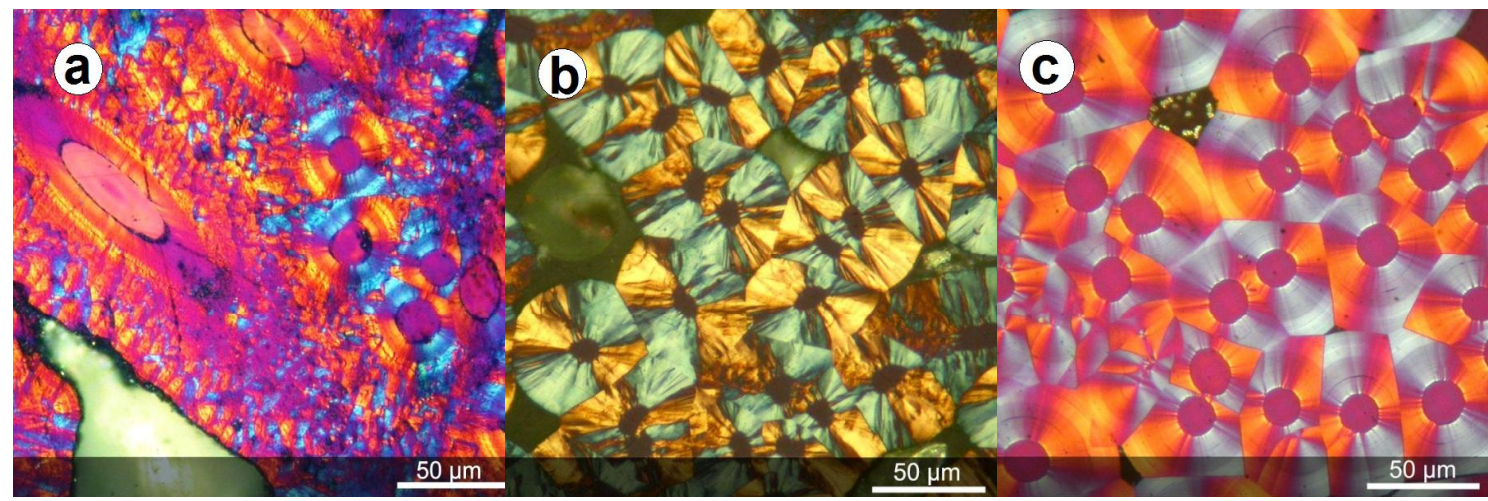

Fig. (6). Comparison of pyrocarbon by PLM (a. DS, b. RL, c. SL).
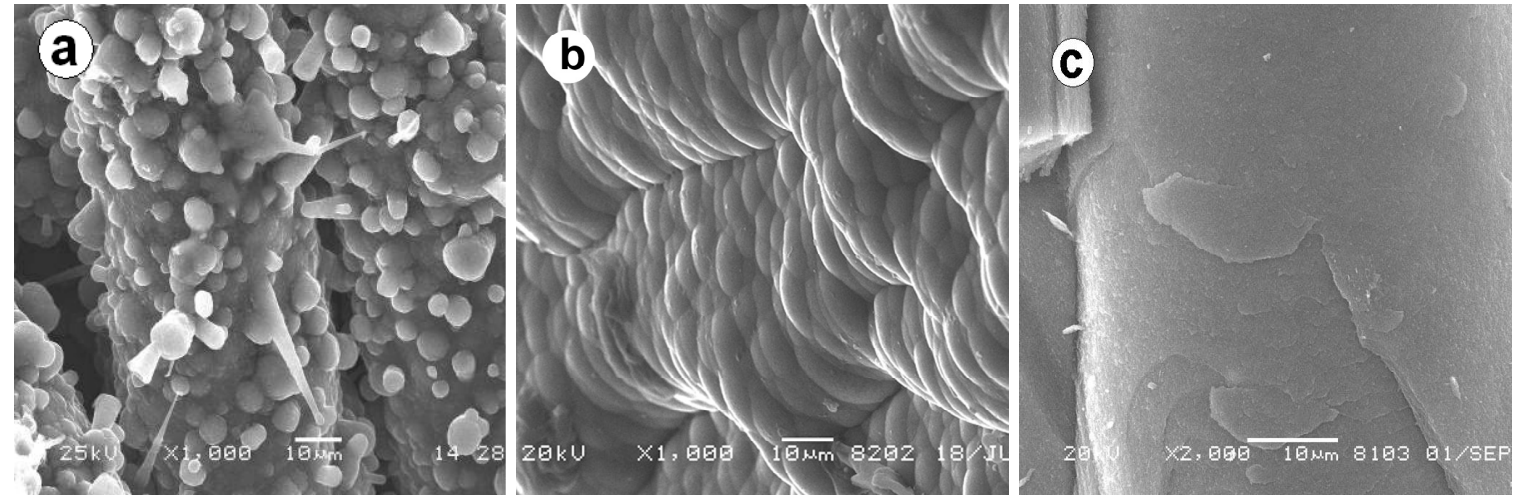

Fig. (7). Surface comparison of pyrocarbon by SEM (a. DS, b. RL, c .SL). 


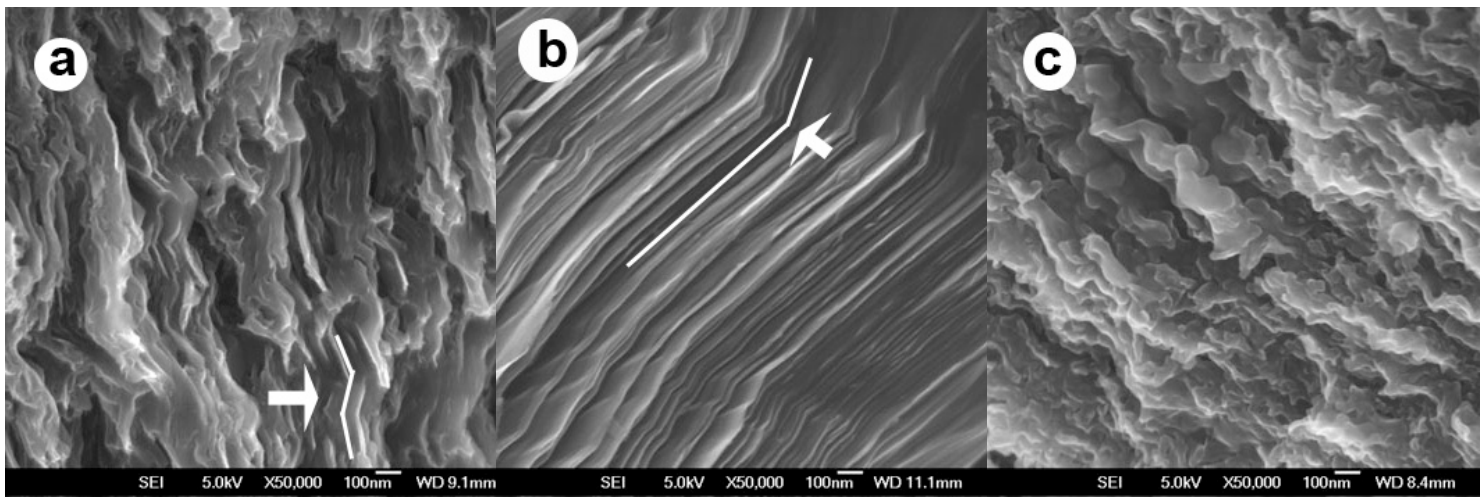

Fig. (8). Cross-section comparison of pyrocarbon by SEM (a. DS, b. RL, c .SL).

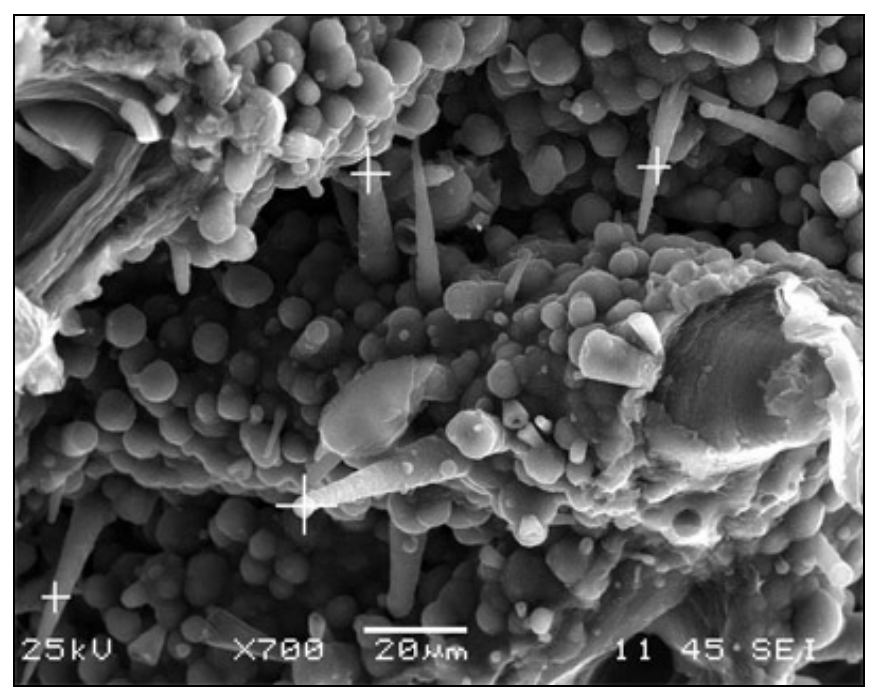

Fig. (9). Energy disperse spectrum of DS pyrocarbon.

carbon is detected that indicates no catalysis effected on the growth of DS pyrocarbon. Based on above results, the DS pyrocarbon is a new carbon formation status.

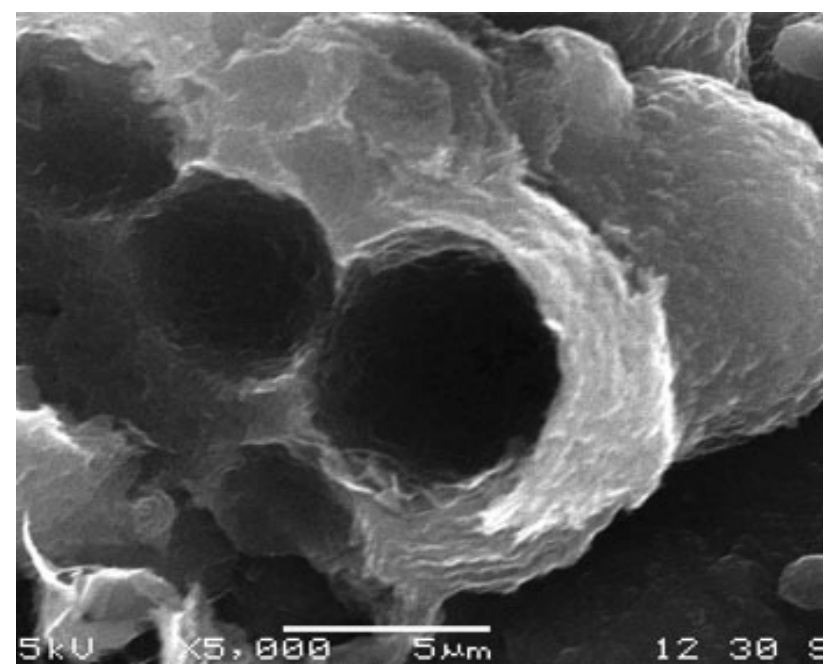

Fig. (10). Vacant sphere of pyrocarbon.

The observation of SEM showed a lot of vacant spheres lie in the nodules as shown in Fig. (10). Latest literature [7] showed hydrogen being formed during hydrocarbons dehydrogenation will get together to press around pyrocarbon and may form gas channel. It can interpret the

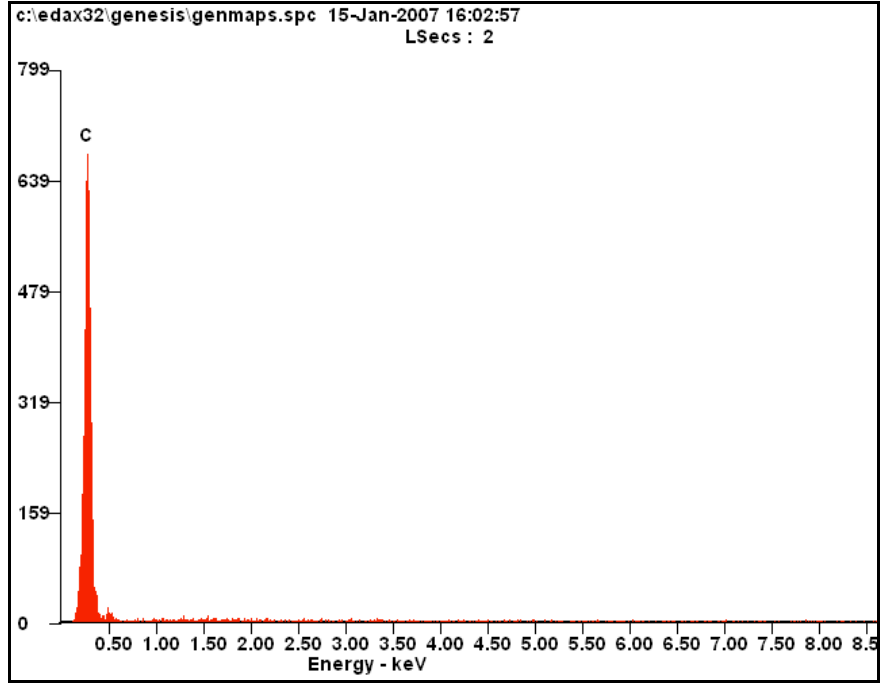

sawtooth wave (Fig. 8a) and the vacant spheres near the surface in the pyrocarbon. It is because of press of the superfluous hydrogen gas and fast deposition rate.

As shown in Fig. (11), the ratio of the D and G peaks, $\mathrm{I}_{\mathrm{G}} / \mathrm{I}_{\mathrm{D}}$ which provides an estimate of the graphite crystallite size is the highest for DS pyrocarbon, conforming that it has more crystalline character. The results strengthen the data of graphitization degree obtained from XRD.

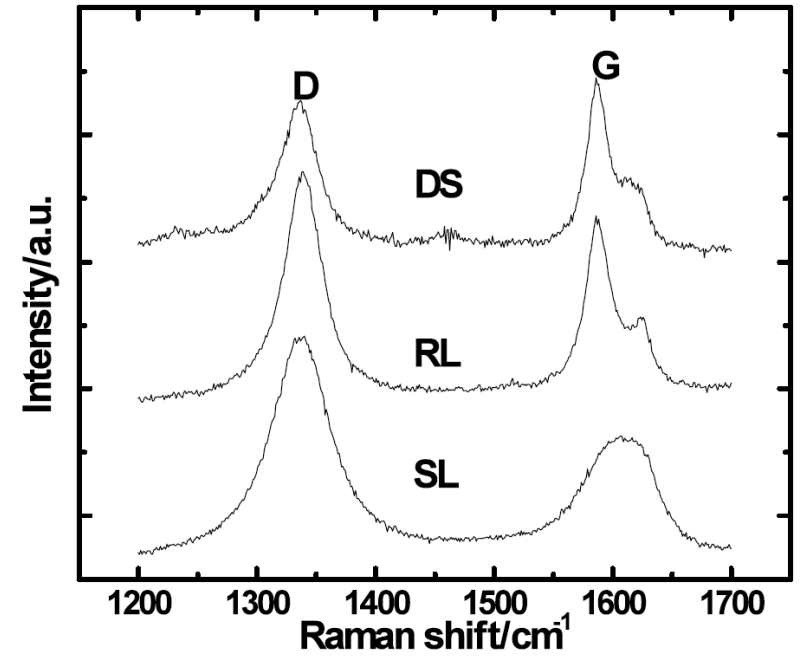

Fig. (11). Raman spectra at different textures. 
During CVI, the formed nodules tend to cause point discharge. Point discharge absorbs the polar particles to deposition surface under the electromagnetic field effect which accelerates the deposition rate, and makes the polar particles rearrange on a fixed direction. While slower surface diffusion and increasing desorption hydrogen led to the formation of more cones, tubes and nodules on the deposition surface. Fig. (12) is the point discharge schematic diagrams.

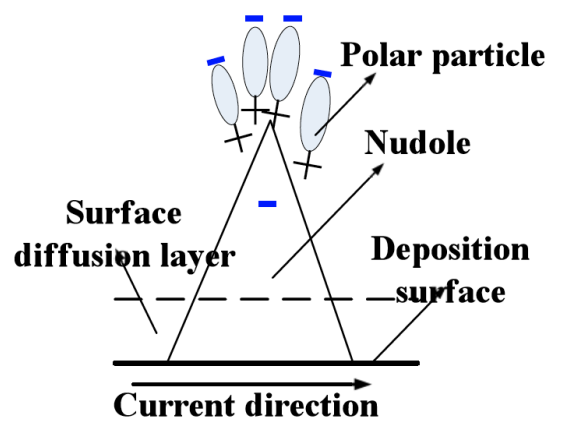

Fig. (12). Schematic diagrams of point discharge.

\section{CONCLUSIONS}

A new surface morpha is grown under control parameters while the DS pyrocarbon position in the traditional classification is still not clear and so it is difficult to give a definition. How big the respective effect of multiple physics fields on deposition rate is also not clear. It is the underway and further work for our team. At the same time, the $\mathrm{C} / \mathrm{C}$ composite with this microstructure is looking forward to be applied to airplane brakes which need a higher graphitization degree. The research on the pyrocarbon is beneficial to understand the mechanism of pyrocarbon deposition during CVI.

\section{ACKNOWLEDGEMENTS}

This work is supported by National Natural Science Foundation of China (Grant No. 50802115 and 51021063) and 973 program of China (Grant No.2011CB605801).

\section{REFERENCES}

[1] Delhaés P. Chemical vapor deposition and infiltration processes of carbon materials. Carbon 2002; 40(5): 641-57.

[2] Lacroix R, Fournet R, Ziegler-Devin I, Marquaire PM. Kinetic modeling of surface reactions involved in CVI of pyrocarbon obtained by propane pyrolysis. Carbon 2010; 48(1): 132-44.

[3] Wu X, Luo R, Zhang J, Xiang Q, Ni Y. Deposition mechanism and microstructure of pyrocarbon prepared by chemical vapor infiltration with kerosene as precursor. Carbon 2009; 47(6): 142935 .

[4] Zhang MY, Huang QZ, Su ZA, Xie ZY. Preparation and Microstructure Analysis of $\mathrm{C} / \mathrm{C}$ Composites with Multi-coupling Fields CVI. J Inorg Mater 2006; 21(6): 1373-7.

[5] Nakamizo M, Kammereck R, Walker Jr PL. Laser raman studies on carbons. Carbon 1974; 12(3): 259-67.

[6] Vallerot J-M, Bourrat X, Mouchon A, Chollon G. Quantitative structural and textural assessment of laminar pyrocarbons through Raman spectroscopy, electron diffraction and few other techniques. Carbon 2006; 44(9): 1833-44.

[7] Reznik B, Norinaga K, Gerthsen D, Deutschmann O. The effect of cooling rate on hydrogen release from a pyrolytic carbon coating and its resulting morphology. Carbon 2006; 44(7): 1330-4. 